EMERGING VOICES

\title{
Approaches to English for Academic Purposes for Non-native Speakers of English
}

\author{
Heba Bakry*
}

\section{English as an Academic Lingua Franca}

The role of English is recognized in many countries officially and unofficially, in everyday life and professional contexts. In 2003, David Crystal numbered a variety of historical, political, commercial, cultural, and technological factors for why English is considered a global language. This widespread use of English has been demonstrated by Kachru (1985) who classified its speakers into belonging to one of three main circles: The Inner Circle, the Outer Circle, and the Expanding Circle. The Inner Circle represents the regions where English is used as a principal language, for example, in the UK, the USA, Australia, Canada, and New Zealand. The Outer Circle represents the regions that were colonized by Britain and the USA where English is an acknowledged formal language used in different everyday life situations as India, Nigeria, the Philippines, and Singapore. The Expanding Circle -which is the largest- includes the areas where English is used as a Lingua Franca (LF) in China, Europe, Japan, Korea, and the Arab world. In 2012, it was estimated that four of the ten countries with the highest proportion of international students (relative to the total university enrollment) were in the Inner Circle: Australia, UK, New Zealand and Canada (Charles, \& Pecorari, 2016).

Although these students may not be majoring in English, most of their studies are in systems that adopt English as a medium of instruction. It is not surprising then that statistically, in 2016, 1500 million people worldwide were speaking English, and only 375 million of them were native speakers (Statista). It is likely that English is used more among those who have been traditionally termed as nonnative speakers than among its native speakers. Therefore, it is of necessity

\footnotetext{
* Assistant Lecturer in the Department of English Language and Literature, Faculty of Arts, Cairo University. This paper is derived from a Ph.D. thesis in progress entitled "The Impact of Genre-based English for Academic Purposes Approach on the Research Writing Competence of Egyptian Scholars", (Cairo University), supervised by Prof. Ola Hafez, Prof. Amani Badawy, and Assoc. Prof. Dr. Randa Anwar Halim.

Cairo Studies in English 2020(1): https://cse.journals.ekb.eg/
} 
to study the features of English as a Lingua Franca (ELF) and how it is related to English for Specific Purposes (ESP).

The term Lingua Franca (LF) referred originally to an old pidgin that consisted of Italian mixed with Greek, Turkish, Spanish, Portuguese, Arabic, and French (Bjorkman, 2013). With limited vocabulary and grammar, the function of this pidgin was very primitive, i.e., to sustain the basic communicative needs of the commercial transactions by the language communities around the Mediterranean. The earlier definitions of ELF excluded the native speakers from its community; for instance, Firth (1996) defined it as "a 'contact language' between persons who share neither a common native tongue nor a common (national) culture, and for whom English is the chosen foreign language of communication" (p. 240). While the original LF did not have a native origin or become even nativized later, the world current LF, English, emerged from a native language that has already been and still is spoken in different communities (the inner, the outer, and the external circles). Accordingly, a more recent and accurate definition of LF was given by Seidlhofer (2010) who defined it as "a mode of communication in its own right, whose users exploit the language in creative ways so as to achieve their communicative purposes and co-construct mutual understanding" (p. 10). Over the years, the multiple nationalities and functions of the users have already been contributing to the language variety that is used now by the speakers of the expanding circle; however, this circle cannot exclude the other two more "native-like" circles. ELF, then, is a variety of English used by both native and non-native speakers in specific communities of speech, for effective commercial and academic purposes.

ELF is used by many scholars as a medium to communicate across borders, hence, the emergence of English as a Lingua Franca in Academia (ELFA). Following the "Publish or perish" saying, to achieve an international readership, scholars pursue publishing in journals and participating in conferences. For instance, in the 1990s, the journal Linguistics Abstracts observed that $70 \%$ of the content of more than 160 journals in linguistics is in English (Crystal, 2003). Currently, the central objective of ELFA research is to "understand the impact of English as an unprecedented global LF in the rest of the world" and "to understand, conversely, the impact on English of the enormous variety of language contact, cultural contact and new centers of power and influence" (p.45). Bjorkman (2013) highlighted the need of native speakers to get accustomed to communicating in ELF international settings to be able to understand the different word choices and grammatical patterns used by the ELF speakers. Academic literacy requires more than just the accuracy and fluency of the speaker because "academic English is no one's native language" (Bourdieu 
and Passeron, 1994, p. 8); hence, exposure to international conferences and publications is essential to acquire its conventions smoothly. This exposure works both ways; it familiarizes the members of the academic speech community with the variety of the used discourse, and it puts this discourse under the lens of critical analysis that contributes to its evolution. As Casanave's (2002) investigation of case studies revealed, in post-graduate departments, academic literacy practices are intertwined with other social practices, and hence, play a significant role in "shaping new identities of students." As a result, students learn to manipulate the rules or "resist being absorbed by academic cultures and subcultures, which at first seem intimidating and impenetrable" (p. 176).

Reinforced by Swales and Feak (2009), being a speaker of ELF, or a speaker of English as an additional language enables the researcher to communicate successfully internationally, since the greater number of "people in today's Anglophone research world do not have English as their first language" (p. xi). Evidence of the dispersal of the non-native ELFA discourse is verified in Swales and Leeder's (2012) study where they analyzed the 15 most cited articles that were published in the 90s in The English for Specific Purposes Journal. They discovered that the article selection did not show any biases to the authors' L1, institutional location, or gender; instead, the field of research (i.e., discoursal features of the text), and the type of ESP (i.e., EAP) were the focal prompting factors. In their study, the two most cited articles were written by non-native women who were not working in famous universities or in Anglophone countries. This fact proves that the opportunities for international publishing are not affected by the researcher's gender, native language, or the status of their institutes. Nonetheless, the focus of teaching EAP seems to be more idiocentric in the sense that it always offers generalized features that are more familiar to the native English speaker rather than the non-native, instead of leaving a room for tolerating the different cultural and linguistic influence from the ELFA community. The EAP academic conventions need to be familiar to a wider range of users not just the native speakers of English. Since ELFA studies will logically rely heavily on the EAP studies, in the following sections a brief introduction of the history and approaches to EAP will be discussed.

\section{Approaches to EAP}

Li and Wang (2016) scrutinized the current EAP literacies that the term denotes, classifying them into four main literacies: traditionalism (EAP as academic literacy), progressivism (EAP as disciplinary), criticalism (EAP as critical literacy) and EAP as digital literacy. The traditional view of EAP sees education as disseminating authoritative and objective knowledge. In this view, 
EAP focuses on teaching scholars the English language and study skills without acknowledging the specificity of the different academic genres as these language and study skills are essentially transferable and generic. Hence, students perceive English as a code and a system, and they practice the generic skills required to complete tasks and assignments in academia. The progressive school is concerned with knowledge as communication between specific individuals in specific contexts- the common knowledge and the conventions used by the speech communities of specific disciplines. It aims at the interaction of the literal meaning (locution), the connotation of the language (illocution), and the results of the communication (perlocution) (Austin, 1962). Accordingly, it requires the active participation of the learners to be proficient in the disciplinary discourse, through guidance and modeling, which is known as "disciplinary socialization" (Li, \& Wang). Derived from modernism and postmodernism, the critical literacy approach to EAP is more liberating. It encourages students to question the norms and acknowledges the cultural and social practices of the academic context. The need to consider the critical approach to EAP arises from the danger of treating disciplinary discourse as static, and students as passive learners, which compensates for the limitations of the traditional approach that may favor native idiocentric conventions and the freer social practice of the learners. In addition, it helps the learners gain a critical understanding of the discipline. Finally, under digitalism, EAP is concerned with teaching students to select, manage and understand resources that, for instance, will help them know how to add markers or footnotes to e-materials, and how to use antiplagiarism programs such as Turnitin. Although they differ in their objectives, these approaches still endorse four key features: authenticity, groundedness, interdisciplinarity, and relevance (Hyland, \& Shaw, 2016).

\section{English for General or Specific Academic Purposes?}

Study skills are the key component in EAP; although non-native students may have already possessed study skills in their native language, they still need to get training on the skills that help them study their disciplines in English (Jordan, 1996). These skills are either "broad", such as guessing word meanings from a text or using the dictionary, or "narrow" such as referencing and formatting skills. Additionally, some of these skills are receptive, such as listening and notetaking, and others are productive, such as presenting a seminar paper and writing papers. Both receptive and productive skills are complementary as the former are seen as necessary inputs to the latter. Still, two problematic issues arise upon designing EAP courses: (a) whether teaching EAP should be further contextualized in the students' specific disciplines, rather than be taught as a 
general discipline on its own, and (b) whether EAP should be taught strictly in contrast to the students' native rhetoric. The dichotomy of broadness versus narrowness should be reflected in the structure of the EAP program itself; it can either be "common core" that it deals with general EAP writing skills, or "subject-specific" that caters to the specific disciplines of the researchers as suggested by Coffey (1984). The dichotomy has been explained further and in more detail by Hyland (2006) in his book, English for Academic Purposes, as English for General Academic Purposes (EGAP) and English for Specific Academic Purposes (ESAP). EGAP is concerned with the main study skills such as "questioning, note-taking, summary writing, and giving prepared presentations", while ESAP focuses on "the skills and language which are related to the demands of a particular discipline or department" (p. 9). Spack (1988) supported the generic view of teaching EAP, arguing that teachers should teach the academic writing process and avoid wasting time in attempting to master the content of other disciplines, in to help students contextualize their academic writing skills. If teachers choose to adopt such a specialized approach, they will have to acquire not only the knowledge of other disciplines and perhaps their sub-disciplines, but also their different conventions including the controversial ones, which will be a weary endeavor after all. Spack, thus, justified a more generalized approach where the teachers offer their students the main tools that, with practical experience in reading and writing, will help them tailor what they know in whichever discipline they study or career they pursue.

On the other hand, Dudley-Evans and St John (1998), and Hyland (2002, \& 2006) argued for specificity, i.e., ESAP. Hyland (2006) showed through reviewing the literature on text analysis and social constructionism that academic discourse is monolithic, "while generic labels such as 'academic English' or 'scientific English' may be a convenient shorthand for describing general varieties, they conceal a wealth of discursive complexity" (p. 392). Specificity then is necessary, even if it is time-consuming and costly, for the sake of effectiveness and professionalism as an "expertise in a subject means being able to use its discourses in the specific ways that one's readers are likely to find effective and persuasive." (p. 393). Dudley-Evans and St John suggested three levels of cooperation between the ESAP instructor and the subject-specific teachers. The first stage involves the language instructor gathering information about the subject from the teachers and the syllabus they teach. The second stage is collaboration where the language instructor and the subject teacher work together outside the classroom. An example of this collaboration is planning several classes where the language instructor prepares the students for a specific task or class in the subject class. The third stage is the team-teaching level, where 
the collaboration happens in the classroom of the language and the subject specialists; for instance, the language teacher might use a recorded lecture in the subject course as a material for a listening task. Finally, Charles and Pecorari (2016) recommended that the specialized teacher should be updated with the recent research in EAP specialized published outlets like Journal of English for Academic Purposes where they can find answers to their questions. They suggested using the term "practitioner" instead of "teacher", since the role of the EAP teacher extends beyond the classroom teaching.

\section{Models of and Approaches to Teaching Academic Writing}

Theorizing literacies in academia led to the development of three main models of teaching writing: the study skills model, the academic socialization model, and the academic literacies model (Lea, \& Street, 1998). The study skills model focuses on the students' deficits through teaching a set of generic academic skills, and it views students' writing as a technical and instrumental skill. The second model, the academic socialization model, promotes the notion that students should acquire academic skills through acculturation, i.e., implicit induction, and, thus, the significance of Hyland's concept of specificity that emphasizes the importance of studying academic writing through the authentic relevant discipline which students' study. Reading the culture means "learning to come to terms with its distinctive rituals, values, styles of language and behavior" (Ballard, \& Clanchy, 1988, p. 8) which is an integral part of academic life. The third model of teaching academic writing, which is academic literacies, adopts a holistic approach to writing, viewing academic life as reflecting matters of epistemology and identity, not just the matters of study skills or discipline socialization. It values more the students' experience and the unequal power relations that help structuring them (Hyland, 2006).

According to their adopted teaching philosophy, teachers can choose to follow one of three main methods of teaching writing: the product, the process, and the genre approaches (Badger, \&White, 2000). In the product approach, the learner learns writing through four main stages: the familiarization with a model text, the controlled and guided writing where the learner practices the skills with graded guidance, and finally comes the free writing stage where the learner is asked to write a genuine piece of writing. Unlike the product approach that focuses on the linguistic knowledge and the language structure, the processbased approach focuses more on the language skills developed in the four stages: prewriting, composing/drafting, revising, and editing (Tribble, 1996, p. 39). A modified approach of the process pedagogy was suggested earlier by Flower and Hayes (1981). In their suggested approach, the cognitive skills of the learners 
should be first activated to be able to follow the three recursive processes: planning, translating, and reviewing. By planning, Flower and Hayes refer to the act of building the internal representation, and it involves the following subprocesses: generating ideas, organizing, and goal-setting. As for translating, it involves "putting the ideas into visible language" (p. 373). Finally, the reviewing stage is a very complex one that relies on reflective reading that assures evaluating the writing with regard to the intended mental representation. The model is based on individual motivation, personal freedom, self-expression, and the learner's responsibility (Hyland, 2003). Consequently, it is usually in favor of L1 speakers who have been socialized into these practices in their early years, "according to a highly child-centered, middle-class form of socialization" (Ramanathan \& Atkinson, 1999, p. 64); in addition, it is in favor of professional L1 speakers who has an enhanced ability to perceive and diagnose problems when revising (Flower et al., 1986).

The third writing approach, which has gained popularity among EAP scholars for it is valuable for post-graduate students in particular, is the genrebased and it is concerned with the social context of the text and its purpose. It stresses the covert dialogue between the writer and the reader's expectations, as the writer co-creates the meaning in view of the reader's interpretation. DudleyEvans and St. John (1998) suggest three basic stages in this approach that, in fact, mirror the teaching/learning cycle (Hyon, 1996): modeling a particular genre, answering exercises focusing on language forms, and eventually producing the text. Hyland (2003) pointed out that the genre-based pedagogies address the deficit of the process approach, which is encouraging individualism for the authors and the writing process itself, by providing students with overt and orderly accounts of the functions of language in realistic social contexts. The chosen criteria for defining any text determine its functions and, subsequently, its method of acquisition or mastery, for genre theory is divergent and multifaceted that it has been the most influential in the field of EAP (Ding, \& Bruce, 2017). For the past 30 years, genre analysis has been a very influential tool in teaching academic and professional genres in the ESP field (Bhatia, 2012). The first introduction of the term "genre" was in the early 1980s and it was part of the ESP field (Paltridge, 2007). It was specifically introduced by Tarone et al. (1981) upon investigating the active and passive forms used in astrophysics journal articles. In their paper, they recommended to investigate the rhetorical functions that condition the choice of the passive in specific English for Science and Technology genres so as to be able to deliver "accurate information" to students of this specialization. Among the early attempts of defining genre analysis was the one adopted by the North American School 
whose concept of genre has been inspired by Miller's (1984) seminal article "Genre as social action." In Miller's groundbreaking article, genre was conceptualized as "a conventional category of discourse based on large-scale typification of rhetorical action and acquiring meaning from the social context of a situation (p. 162)". Bhatia (2002) blended the major perspectives of defining "genre analysis". He defined it as "the study of situated linguistic behavior in institutionalized academic or professional settings, whether in terms of typification of rhetorical action [as suggested in Miller's definition], regularities of staged, good oriented social processes; or consistency of communicative purposes" (p. 23). Bhatia synthesizes the different approaches to be oriented towards emphasizing its conventional and dynamic nature, for he believes that any description of a language should include lexicogrammatical features, a specific genre, and a target social practice. The importance of genre studies was further highlighted by Bazerman (2000, p. 16) as

in recognizing a text type, we recognize many things about the institutional and social setting, the activities being proposed, the roles available to writer and reader, the motives, ideas, ideology, and expected content of the document, and where this all might fit in our life.

Hence, genre analysis is a useful preliminary step towards understanding genre pedagogies as it links the textual and sociocultural contexts. Accordingly, adopting genre pedagogy by explaining how moves occur and observing the rhetorical and structural organization of texts explains the ways discourse communities achieve their social purposes.

Badger and White (2000) recommend integrating the insights of the product, the process and the genre approaches towards a process-genre approach where the "writing involves knowledge about language (as in product and genre approaches), knowledge of the context in which writing happens and especially the purpose for the writing (as in genre approaches), and skills in using language (as in process approaches)" (p. 157-158). The rationale for this approach is that the students develop their writing skills differently and the needed input will, consequently, depend on the learner's prior knowledge of the genre. The teacher's role provides the appropriate input of skills and knowledge that enhances the learners' progress. 


\section{Culture: BIG \& Small}

Apart from the general culture represented ethno-linguistically, it is also worthy to attend to the learners' small culture that in an academic setting would be the university. It will be more governing than their general cultural affiliations that are associated with nationality, race, or religion, for example. The term "small culture" was coined by Holliday in 1999; it differs from the static "default notion of culture that refers to prescribed ethnic, national and international entities" (p. 237). For Holliday, the small culture is dynamic and has "more to do with activities taking place within a group than with the nature of the group itself" (p. 250). It encompasses any intercultural situation such as the academic one, i.e., classroom, discipline, youth, and student. In other words, the concept of the small culture extends beyond the boundaries of the big one; the students are no longer JUST Arabs, Egyptians, or Muslims. It is true that they may have a lot to share, yet each student has his/her own culture that is shaped by his/her neighborhood, experiences, educational system, socio-economic class, ideology, specialization...etc. Understanding the small culture of the student, thus, ensures continuity rather than dichotomy (Atkinson, 2003), which should lead to a better understanding of the students' needs. This approach is reflected in the type of exercises that are offered, not only to introduce new concepts but also to lessen the cultural gap that causes frustration to many graduates and postgraduates in local or international settings.

\section{Studies on Arab Learners}

Many university students suffer from the repercussions of lacking the necessary linguistic and cognitive background that should help them conceive new genres and concepts to which they were not introduced in their schools. This is in addition to the fact that they are more familiar with the rhetoric of their native language (Arabic) which appreciates repetition and metaphorical clichés than with that of their second/foreign language (English) which condemns repetition and clichés (Ahmed, 2010). They do not suffer only from the transfer of the rhetorical devices, but also from the systemic differences between the two languages that can hamper the acquisition of certain lexical items. For instance, the differences in the vowel system in English and Arabic have had their effect on the vocabulary acquisition of Arab learners because of the system of diacritical marks in Arabic. The learners process the English short and long vowels in the same way they do in Arabic, which results in mis-spelling and unrecognizing the English words (Saigh, \& Schmitt, 2012). Salim's study (2013) compared the English-Arabic noun morphology and concluded that both 
languages share some features, such as using almost the same morphological processes, having the same number of word classes, and having one form of the 1st person singular plural. However, they still share differences, such as the derivational system of Arabic, "which may cause a few difficulties for the second language learners" (p.131).

Moreover, due to the dominant exposure to English-speaking movies (and particularly from Hollywood), students become more used to the informal rhetoric of English than to the formal academic one. After conducting interviews, and giving them three linguistic tests to measure their English grammar and vocabulary knowledge, Egyptian EFL university students in Abdel-Latif 's (2007) study revealed these causes of writing apprehension: having a poor history of writing achievement and perceived writing performance improvement, lacking linguistic knowledge (grammar and vocabulary), acquiring low EFL competence level and low English writing self-efficacy, and fearing criticism. In another study and upon interviewing 50 male undergraduate students majoring in English about writing in English at the University of AlAzhar (Salem, 2007), students justified their overwhelmed feelings when writing on a given topic by their incompetence in knowing how to start or how to develop their thesis in English. Consequently, they find themselves repeating ideas, reporting few if any supporting evidence, making severe language mistakes, and including irrelevant details.

At Helwan University in Egypt, El-Deeb (2007) designed a course to develop the required study skills for Special Diploma students. According to El-Deeb, most English language programs which catered to the needs of postgraduate students focus on general English (EFL). The study identified the English language needs of these students, designed an EAP program to develop the required study skills, and assessed its effectiveness. The results of the study showed that EGAP is an effective method for designing English language programs for nonnative graduate students; it helped improving their language proficiency and deepening their academic achievement since students prefer to relate the language to their specializations. Finally, the study highlighted the significance of using authentic texts and activities, since they stimulated the students' positive involvement.

As for the specificity of writing academic genres by scholars, Seleem (2013) analyzed 47 research articles published by Egyptian scholars in local Egyptian medical journals and compared them to the Corpus of Contemporary American English (COCA), to investigate the use of direct self-reference. The study showed a tendency of the Egyptians to sound "more distant and cautious" by avoiding first-person singular pronouns and using more mitigated and 
impersonal structures and verbs. Seleem explained that this is done "due to some cultural influences, or due to lack of linguistic awareness, [as they] are more comfortable feeling disguised within a larger group of contributors, hence, feeling less imposition in the direct self-reference" (p. 101). Moreover, the influence of Arabic was vibrant in the use of the word "results" instead of "findings" as the former is closer to the literal translation of the word in Arabic. Yet, there was evidence of agreement between the two corpora, for the Egyptian scholars showed an awareness of the "second top preference, simple past tense" and "the use of longer construction of the existential "it" clause (p. 102).

\section{Conclusion}

In an open postmodern digital era where international English publications are more than there have ever been, teaching EAP as objective static Anglocentric knowledge does not help the majority of the scholars worldwide. It is of significance to study the features of ELFA, with a progressive and critical approach that allows for inclusion more than exclusion. Studying the publications of non-native speakers of English thoroughly and using them in teaching EAP should help in familiarizing the young scholars with the expected linguistic features of their writings. Concerning EGAP and ESAP as approaches, although they may seem contradictory, they are in fact complementary to each other. An introductory EGAP course is fundamental at the beginning to acquire general study skills, like note-taking, brainstorming, outlining, paraphrasing, and summarizing. These skills should cater for the needs of the nonnative speaker, and they should facilitate acquainting them with their academic discourse communities. In the EGAP class, in order to bring closer the new concepts and skills introduced in academic writing, teachers need to be aware of the everyday rhetoric used by their students to relate to it instead of denouncing it. This method will enhance the students' self-efficacy, as they will learn how to tackle language. After getting this proper training, ESAP will be effective in contextualizing these skills in specific genres. Students will have ample time to analyze and produce the register used in their academic career. At this stage, international publications of non-native speakers can be used as examples of the accepted form and style of the field. For instance, an ESAP course in the context of the humanities will include typical text types, such as essays, critical analysis, translations and projects, in addition to reports, and fieldwork notes and all in the context of social sciences (Coffin, 2003). Therefore, a systematic approach from EGAP to ESAP will help them utilize the skills they already acquired at ease previously in more sophisticated writings whether academic or professional. 
Upon examining these three previously discussed methods, i.e., the study skills model, the academic socialization model, and the academic literacies model (Lea \& Street, 1998), it can be deduced that the three models move from the explicit direct approach of spoon-feeding the students with the required skills to the more implicit approach that lauds the whole experience and gives the students the freedom to critically choose what would best represent their discourse community. A hierarchical eclectic approach should be more efficacious, with the study skills model adopted in the beginning of the course (as in the EGAP approach), followed by the socialization model (as in the ESAP approach) in the transition stage, before the students are given the opportunity to critically discern and appraise their academic community and consequently befit their writing according to what is acceptable to it.

To conclude, practices and preferences that are common in one discipline or culture are not in another. There is evidence that the formal conventions of the academic genre writing are changing slowly to be more engaging and personal, which may confuse the novice nonnative scholar (Hyland, \& Jiang, 2017). As the empirical literature on the academic production of speakers of Arabic shows, rhetorical and cultural influences do exist, and still the differences do not obstruct successful endeavors from publication. Thus, a needs assessment is needed before planning an eclectic progressive approach that asserts acculturation through authentic discipline-relevant texts should improve the students' academic writing proficiency and will qualify them for a friendlier publishing platform.

\section{References}

Abdel-Latif, M. (2007). The factors accounting for the Egyptian EFL university students' negative writing affect. Essex Graduate Student Papers in Language \& Linguistics, 9(7), 57-82.

Ahmed, A. (2010). Contextual challenges to Egyptian students' writing development. International Journal of Arts and Sciences, 3(14), 503-522.

Atkinson, D. (2003). Writing and culture in the post-process era. Journal of Second Language Writing, 12(1), 49-63.

Austin, J. L. (1962). How to do things with word. London: Oxford University Press.

Badger, R., \& White, G. (January 01, 2000). A process genre approach to teaching writing. ELT Journal (United States), 54(2), 153-160. 
Ballard, B., \& Clanchy, J. (1988). Literacy in the university: an anthropological approach. In G. Taylor (Ed.), Literacy by Degrees (pp. 7-23). Milton Keynes: Society for Research into Higher Education and Open University Press.

Bazerman, C. (2000). Letters and the social grounding of differentiated genres. In D.Barton \& Nigel Hall (Eds.), Letter writing as a social practice (pp. 1529). Philadelphia: John Benjamins Pub

Bhatia, V. K. (2002). A generic view of academic discourse. In J. Flowerdew (Ed.) Academic discourse (pp. 21-39). London: Pearson Education Limited.

Bhatia, V. K. (2012). Critical reflections on genre analysis. Ibérica, 24, 17-28.

Bjorkman, B. (2013). English as an Academic Lingua Franca. Berlin: De Gruyter Mouton.

Bourdieu, P., \& Passeron, J. C. (1994). Introduction: Language and the relationship to language in the teaching situation. In P. Bourdieu, J.C. Passeron, \& M. de St. Martin (Eds.), Academic discourse (pp. 1-34). Cambridge: Polity Press.

Casanave, C. P. (2002). Writing games: Multicultural case studies of academic literacy practices in higher education. Mahwah N.J: L. Erlbaum.

Charles, M., \& Pecorari, D. (2016). Introducing English for Academic Purposes. London: Routledge.

Coffey, B. (1984). ESP-English for Specific Purposes. Language Teaching, 17 (1), 2-16. https://doi.org/10.1017/S0261444800010405

Coffin, C. (2003). Teaching academic writing: A toolkit for higher education. London: Routledge.

Crystal, D. (2003). English as a global language (2nd ed.). Cambridge: Cambridge University Press.

Ding, A., \& Bruce, I. (2017). The English for academic purposes practitioner: Operating on the edge of academia. Cham: Springer International Publishing. Dudley-Evans, T., \& St John, M.J. (1998). Developments in English for Specific Purposes: A multi-disciplinary approach. Cambridge: Cambridge University Press.

El Deeb, E. M. E. S. (2007). The effectiveness of an English for academic purposes programme on developing the required study skills of postgraduate students at the Faculty of Education, Helwan University. Unpublished doctoral dissertation. Helwan University, Cairo, Egypt.

Firth, A. (1996). The discursive accomplishment of normality: On 'lingua franca' English and conversation analysis. Journal of Pragmatics, 26, 237259.

Flower, L., \& Hayes, J. R. (1981). A cognitive process theory of writing. College Composition and Communication, 32(4), 365-387. 
Flower, L., Hayes, J. R., Carey, L., Schriver, K., \& Stratman, J. (1986). Detection, diagnosis, and the strategies of revision. College Composition and Communication, 37, 16-55.

Holliday, A. R. (1999). Small cultures. Applied Linguistics, 20, 237-264.

Hyland, K. (2002). Specificity revisited: How far should we go now? English for Specific Purposes, 21, 385-95.

Hyland, K. (2003). Genre-based pedagogies: A social response to process. Journal of Second Language Writing, 12(1), 17-29.

Hyland, K. (2006). English for Academic Purposes: An advanced resource book. London; New York: Routledge.

Hyland, K., \& Jiang, F. (2017). Is academic writing becoming more informal? English for Specific Purposes, 45, 40-51.

Hyland, K., \& Shaw, Ph. (2016). Introduction. In K. Hyland \& Ph. Shaw (Eds.) The Routledge handbook for English for Academic Purposes. New York: Routledge.

Hyon, S. (1996). Genre in three traditions: Implications for ESL. TESOL Quarterly, 3(4), 693-722.

Jordan, R. R. (1996). English for academic purposes: A guide and resource book for teachers. Cambridge: Cambridge University Press.

Kachru, Y. (1985). Applied linguistics and foreign language teaching: A nonWestern perspective. (ERIC Document Reproduction Service No. ED 256175).

Lea, M., \& Street, B. (1998). Student writing in Higher Education: An academic literacies approach. Studies in Higher Education, 23(2), 157-172.

Li, Y., \& Wang, L. (2016). English for Academic Purposes: A new Perspective from multiple literacies. World Journal of English Language, 6(2), 10-18.

Miller, C. R. (1984). Genre as social action. Quarterly Journal of Speech, 70, 151-167. Retrieved from http://www4.ncsu.edu/ crm/Publications/genre84.pdf

Paltridge, B. (2007). Approaches to genre in ELT. In J. Cummins \& Ch. Davison (Eds.), International handbook of English language teaching, (pp. 931-43). New York: Springer.

Ramanathan, V., \& Atkinson, D. (1999, January 01). Individualism, academic writing, and ESL writers. Journal of Second Language Writing, 8(1), 45-75. https://doi.org/10.1016/S1060-3743(99)80112-X.

Saigh, K., \& Schmitt, N. (2012). Difficulties with vocabulary word form: The case of Arabic ESL learners. System, 40(1), 24-36.

Salem, M. (2007). The effect of journal writing on written performance, writing apprehension, and attitudes of Egyptian English majors (doctoral 
dissertation). The Pennsylvania State University, College of Education, USA. Retrieved from https://etda.libraries.psu.edu/paper/7894/3200.

Salim, J. A. (2013). A contrastive study of English-Arabic noun morphology. International Journal of English Linguistics, 3(3), 122-132. doi:10.5539/ijel.v3n3p122.

Seidlhofer, B.( 2010). Giving VOICE to English as a Lingua Franca. In R. Facchinetti, D. Crystal, \& B. Seidlhofer (Eds.), From international to local English and back again (pp. 147-163) Frankfurt: Peter Lang.

Seleem, S. A. (2013). A corpus analysis of stance marker use in international and Egyptian medical research articles. Unpublished Master's thesis, American University in Cairo, Egypt.

Spack, R. (1988). Initiating ESL students into the academic discourse community: How far should we go? TESOL Quarterly, 22(1), 29-52.

Statista. (n.d.). Most spoken languages in the world. Retrieved October 02, 2016, from https:/www.statista.com/statistics/266808/the-most-spoken-languagesworldwide/

Swales, J. M., \& Leeder, C. (2012). A reception study of the articles published in English for Specific Purposes from 1990-1999. English for Specific Purposes, 31(2), 137-146.

Swales, J., \& Feak, Ch. (2009). Abstracts and the writing of abstracts. Ann Arbour: The University of Michigan Press.

Tarone, E., Dwyer, S., Gillette, S., \& Icke, V. (1981). On the use of the passive in two astrophysics journal papers. The ESP Journal, 1(2), 123-140.

Tribble, C. (1996). Writing. Oxford: Oxford University Press. 